\title{
Crescimento e fitomassa da beterraba sob irrigação suplementar com água de diferentes concentrações salinas
}

\author{
Daniella Pereira dos Santos ${ }^{1 *}$, Célia Silva dos Santos ${ }^{1}$, Patrícia Ferreira da Silva ${ }^{2}$, \\ Mirian Paula Medeiros André Pinheiro ${ }^{3}$, Jandir Cruz Santos ${ }^{4}$
}

$10.1590 / 0034-737 X 201663040011$

\section{RESUMO}

O uso da água salina na agricultura é uma alternativa viável, tendo-se em vista o aumento da demanda de água doce. Objetivou-se, com este trabalho, avaliar o crescimento e a produção de fitomassa da beterraba, sob irrigação com água de diferentes concentrações salinas, em experimento em condição de campo, no Campus da Universidade Federal de Alagoas, em Arapiraca. Os tratamentos foram cinco níveis de condutividade elétrica (1,0; 2,0; 3,0; 4,0 e 5,0 dS m²). O delineamento foi em blocos casualizados, com quatro repetições. O máximo rendimento da beterraba aos 27 dias após aplicação dos tratamentos salinos foi obtido com uma salinidade de $3,0 \mathrm{dS} \mathrm{m}^{-1}$, para as variáveis altura de planta (AP), diâmetro do caule (DC), comprimento da raiz (CR), fitomassa seca da parte aérea (FSPA) e fitomassa seca total (FST). Aos 42 dias após aplicação dos tratamentos salinos, as variáveis fitomassa fresca da parte aérea (FFPA), fitomassa fresca da raiz (FFR), fitomassa fresca total (FFT), fitomassa seca da parte aérea (FSPA) e fitomassa seca total (FST) aumentaram com o aumento da salinidade da água. A chuva pode ter influenciado os resultados obtidos para as avaliações, realizadas aos 42 dias após aplicação dos tratamentos salinos.

Palavras-chave: Beta vulgaris L.; condutividade elétrica; qualidade da água.

\section{ABSTRACT}

\section{Beet growth and biomass under supplementary irrigation with water of different saline concentrations}

The use of saline water in agriculture is a viable alternative in view of the increased freshwater demand. The objective was to evaluate the growth and biomass of beet under irrigation with water of different saline concentrations, in an experiment conducted under field condition in the campus of the Universidade Federal de Alagoas - Arapiraca. The treatments were five levels of electrical conductivity ( 1 1: 1.0, S2: 2.0, S3: 3.0; S4: 4.0; S5: $\left.5.0 \mathrm{dS} \mathrm{m}^{-1}\right)$. The maximum yield of beets at 27 days after saline treatments was obtained with salinity of $3.0 \mathrm{dS} \mathrm{m}^{-1}$, for the variables plant height $(\mathrm{PH})$, stem diameter (SD), root length (RL), shoot dry biomass (SDB), and total dry biomass (TDB). At 42 days after application of saline treatments, the variables shoot fresh biomass (SFB), root fresh biomass (RFB), total fresh biomass (TFB), shoot dry biomass (SDB), and total dry biomass (TDB) increased with increasing salinity. Rain may have influenced the results obtained for the evaluations performed at 42 days after application of saline treatments.

Key words: Beta vulgaris L.; electrical conductivity; water quality.

\footnotetext{
Submetido em 05/05/2015 e aprovado em 04/04/2016.

${ }^{1}$ Universidade Federal Rural de Pernambuco, Departamento de Engenharia Agrícola, Recife, Pernambuco, Brasil. daniellapsantos@hotmail.com; celia_agron@hotmail.com;

${ }^{2}$ Universidade Federal de Campina Grande, Departamento de Engenharia Agrícola, Campina Grande, Paraíba, Brasil. patriciafssilva@hotmail.com

${ }^{3}$ Universidade Estadual Paulista "Júlio de Mesquita Filho", Departamento Ciências Agronômicas, Botucatu, São Paulo, Brasil. mirian-mp@hotmail.com

${ }^{4}$ Universidade Estadual Paulista "Júlio de Mesquita Filho", Departamento Ciências Agronômicas, Jaboticabal, São Paulo, Brasil. jandir_jc@hotmail.com

*Autora para correspondência: daniellapsantos@hotmail.com
} 


\section{INTRODUÇÃO}

A irrigação é um instrumento efetivo para o aumento da produtividade e para a expansão de fronteiras agrícolas, porém sua utilização inadequada pode causar a salinização dos solos, principalmente em regiões áridas e semiáridas, diminuindo os rendimentos das culturas, ou, até mesmo, resultando no abandono das terras. A salinização e sodificação é problema com reflexos econômicos, sociais e ecológicos (Ferreira et al. 2006).

Segundo Silva et al. (2012), a salinidade induzida pelo homem é a que traz maiores prejuízos econômicos, pois ocorre em áreas nas quais se realizaram investimentos elevados, como sistemas de irrigação e fertilizações. A salinidade induzida está geralmente associada ao manejo inadequado da irrigação e da fertirrigação, podendo ser causada tanto pela baixa qualidade da água de irrigação quanto pela aplicação excessiva de fertilizantes ao solo.

É necessário buscar tecnologias alternativas para o uso condizente dessas águas salinas, com seu maior aproveitamento na produção vegetal, diminuindo os impactos ambientais (Santos et al., 2010). Uma alternativa proposta é a utilização de culturas tolerantes à salinidade para produção vegetal intensiva.

Utilizada em diversas regiões semiáridas do mundo, a beterraba (Beta vulgaris L.) é uma opção para produção em condições de solos salinos (Katerji et al., 1997), visto que, além de se destacar por sua composição nutricional, sobretudo em açúcares e pela forma de consumo da raiz tuberosa, ela se apresenta como uma das hortaliças tolerantes a elevados teores de sais (Aquino et al., 2006).

Segundo Ayers \& Westcot (1991), a beterraba apresenta valores de salinidade limiar (CE) de 7,0 dS m${ }^{-1}$, tornando-se mais tolerante ao excesso de sais em estádios avançados de crescimento. Por essa razão, a utilização dessa cultura pode servir como alternativa de renda ao produtor rural com problemas de salinidade na água.

Apesar de sua importância econômica, existem poucos trabalhos que estudam o efeito da salinidade sobre a cultura, particularmente estudos do crescimento e do desenvolvimento inicial da beterraba sob estresse salino e seu potencial para cultivo em condições de campo salinizado por manejo incorreto da irrigação.

Por essa razão, objetivou- se, com este trabalho, avaliar o crescimento e a produção de fitomassa da beterraba, sob irrigação com água de diferentes concentrações salinas.

\section{MATERIAL E MÉTODOS}

O experimento foi desenvolvido em condições de campo, em área pertencente à Universidade Federal de Alagoas (UFAL), Campus Arapiraca, nas coordenadas de 9 45'58”S e $35^{\circ} 38^{\prime} 58^{\prime \prime} \mathrm{O}$, em altitude de $264 \mathrm{~m}$. Esta região é representada pela transição entre Zona da Mata e o Sertão
Alagoano, cujo clima é, de acordo com a classificação de Köppen, tropical com estação seca de Verão.

Os dados diários de precipitação pluvial e umidade relativa do ar do município de Arapiraca, AL, referentes ao período de março a maio de 2010, época correspondente à condução do experimento, foram obtidos do Instituto Nacional de Meteorologia (INMET) e encontram-se apresentados na Figura 1. As temperaturas do ar máxima, média e mínima, referentes ao período de condução do experimento, obtidas do Instituto Nacional de Meteorologia (INMET), estão apresentadas na Figura 2.

O solo utilizado na pesquisa foi classificado como Argissolo Vermelho distrófico (Embrapa, 2013) e suas características químicas, na profundidade de 0-20 cm, estão apresentadas na Tabela 1 .

O delineamento estatístico adotado foi o de blocos casualizados completos, com quatro repetições. Os tratamentos foram constituídos da combinação de cinco níveis de salinidade da água de irrigação (S1: 1; S2: 2; S3: 3; S4: 4 e $\mathrm{S} 5$ : $5 \mathrm{dS} \mathrm{m}^{-1}$ ), com quatro repetições. Os tratamentos foram dispostos em 40 vasos, sendo cada parcela constituída por dois vasos de $2 \mathrm{~L}$, espaçados de $0,5 \mathrm{~m}$ entre vasos e $0,9 \mathrm{~m}$ entre linhas dos vasos. As águas de diferentes concentrações salinas foram obtidas a partir de adições de cloreto de sódio $(\mathrm{NaCl})$ à água de abastecimento, calculadas conforme a equação 1, proposta por Richards (1954).

$C=640 * C E a$

em que:

$\mathrm{C}=$ concentração de $\mathrm{NaCl}\left(\mathrm{mg} \mathrm{L}^{-1}\right)$;

$\mathrm{CEa}=$ Condutividade elétrica da solução $\left(\mathrm{dS} \mathrm{m}{ }^{-1}\right)$.

O cultivar de beterraba utilizado foi o "Early Wonder. As mudas foram produzidas em bandejas de polietileno expandido, de 128 células, preenchidas com substrato composto de casca de arroz e húmus de minhoca, na proporção de 1:1. O transplantio foi realizado, utilizando-se uma muda por vaso, quando apresentava de quatro a cinco folhas definitivas, o que ocorreu por volta dos 25 dias após a semeadura.

Antes do plantio, foi efetuada uma irrigação, para elevar o solo à capacidade de campo, sendo coletado o solo dos vasos, seguindo-se o método gravimétrico (padrão) de estufa, em que foi obtida uma umidade na capacidade de campo de $U=26,32 \%$. As irrigações foram realizadas diariamente sempre no final da tarde e foi aplicado água apenas no solo.

O volume de água consumido foi calculado na manhã do dia seguinte, pela diferença entre o volume de água aplicado e o drenado. Estimou-se a evapotranspiração da cultura (consumo), determinado diariamente. Assim, o volume de água a ser aplicado foi calculado com base no consumo do dia anterior. 
De acordo com a equação 2 de Rhoades (1974), e fração lixiviação 0,15 , foram obtidos os tratamentos para esta fonte de variação. Consequentemente, foi realizado cálculo idêntico para fração lixiviação 0,20, caracterizando-se, assim, dez tratamentos com as concentrações salinas. De acordo com a necessidade hídrica, esse valor variou com cada etapa do ciclo da cultura.

$$
\mathrm{VI}=\frac{\mathrm{VA}-\mathrm{VD}}{1-\mathrm{FL}}
$$

em que:

VI - Volume de água a ser aplicada na irrigação $(\mathrm{mL})$;

VA - Volume de água aplicado na irrigação anterior ou no período $(\mathrm{mL})$;

VD - Volume de água drenada na irrigação anterior ou no período (mL);

FL - Fração de lixiviação $(0,15$ e 0,20$)$.
A irrigação foi realizada manualmente, com proveta graduada para medir as quantidades a serem aplicadas e drenadas diariamente.

As avaliações foram realizadas aos 27 e 42 dias após aplicação dos tratamentos salinos. As plantas de cada unidade experimental foram colhidas separadamente e acondicionadas em sacos de papel previamente identificados, transportados para o Laboratório de Física do Solo da UFAL, onde foram analisadas as variáveis: - altura de planta (AP), mensurada do colo da planta até a base da última folha emitida, com régua graduada em cm; - número de folhas por planta (NF), por meio de contagem direta; diâmetro do caule, mensurado com paquímetro graduado; - área foliar $\left(\mathrm{cm}^{2}\right)$, por meio de um integrador eletrônico de área foliar, modelo LI-3100; - comprimento da raiz (CR), medido com régua graduada, - fitomassas fresca de parte aérea, de raiz e total; - fitomassas secas de parte aérea, de raiz e total.

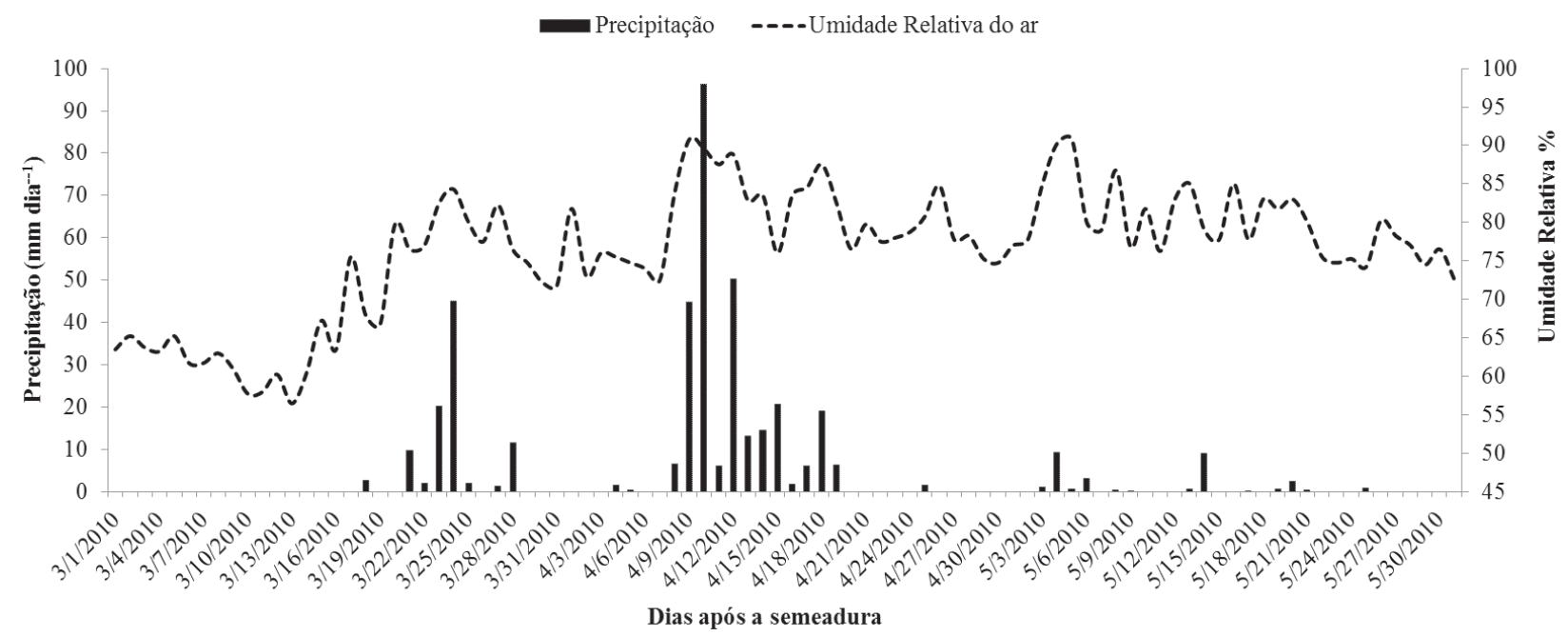

Figura 1: Precipitação pluvial e umidade relativa do ar durante o período de condução do experimento.

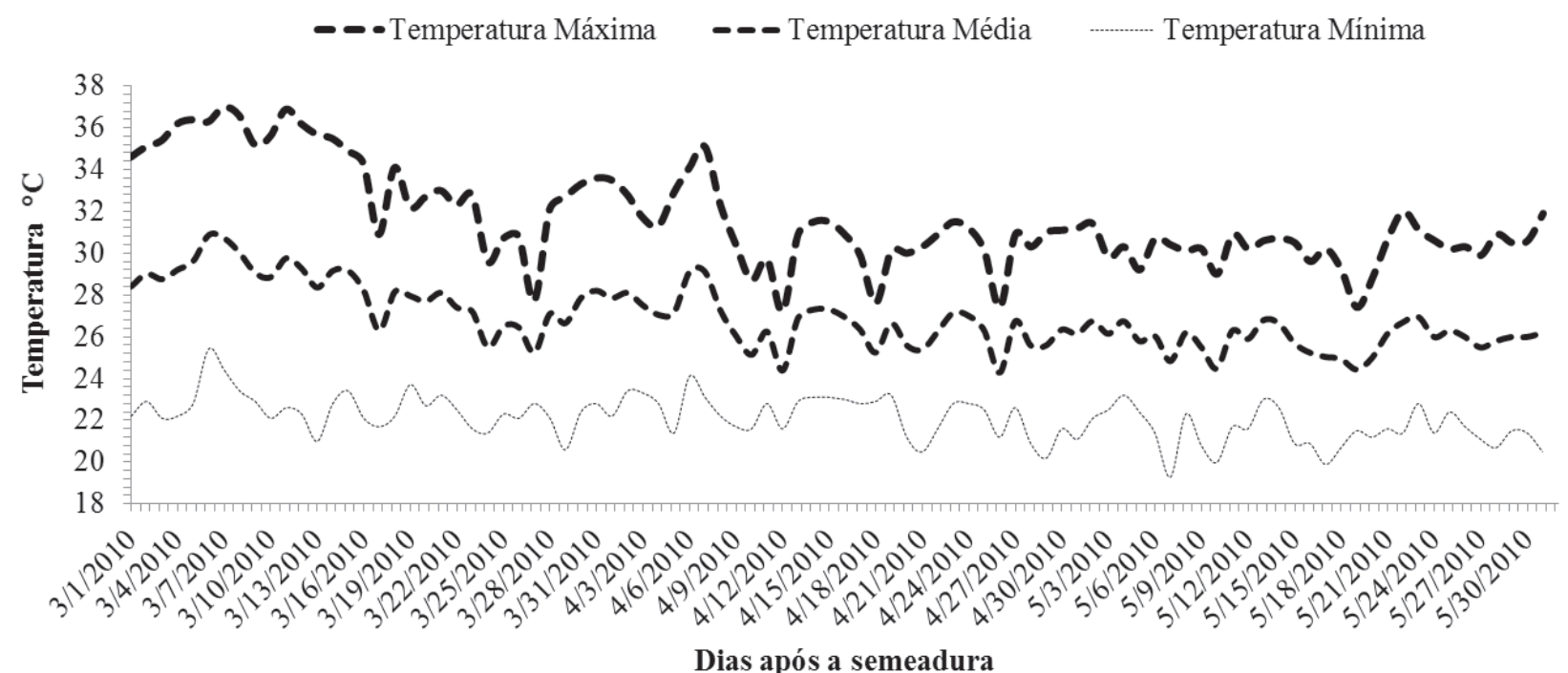

Figura 2: Temperaturas do ar máxima, média e mínima durante o período de experimentação. 
Para obtenção dessas variáveis, as plantas foram retiradas dos vasos, preservando-se suas estruturas, evitando-se danos, tanto para a parte radicular quanto para a parte aérea. Para determinação das fitomassas fresca e seca da raiz e de parte aérea, as plantas foram retiradas dos vasos e lavadas, as raízes e a parte aérea foram pesadas separadamente.

Em seguida, foram acondicionadas em sacos de papel e colocadas em estufa com circulação forçada de ar, a $65^{\circ} \mathrm{C}$, por 48 horas, para posterior pesagem em balança analítica de precisão de $0,01 \mathrm{~g}$. As fitomassas frescas e secas totais foram obtidas com a soma das respectivas massas frescas e secas.

Os resultados foram submetidos à análise de variância pelo teste $\mathrm{F}$, sendo as médias comparadas pelo teste de Tukey, a 5\% com o Software estatístico SISVAR (Ferreira, 2008); para o fator níveis de salinidade realizou-se teste de regressão (por polinômios ortogonais), com níveis de significância de 0,01 ou 0,05 de probabilidade.

\section{RESULTADOS E DISCUSSÃO}

Houve efeito da salinidade $(\mathrm{p}<0,01)$ sobre as variáveis AP, AF, FFPA FSPA, e FST, respectivamente. Houve efeito quadrático significativo ( $p<0,01$ ) sobre AP, DC, AF, CR, FSPA e FST, em função da salinidade da água de irrigação.

De acordo com a equação de regressão para a altura de planta, Figura 3A, a máxima altura foi obtida com 3,11 dS m${ }^{1}$, o que corresponde a 12,8 cm aos 27 dias após aplicação dos tratamentos salinos.

O modelo matemático que melhor se ajustou para diâmetro do caule foi o quadrático (Figura 3B). O máximo diâmetro do caule, aos 37 dias após aplicação dos tratamentos, ocorreu com 3,0 dSm${ }^{-1}$, correspondendo 0,33 mm.

Em estudos como o de Silva (2012), atribui-se a redução dos valores de diâmetro do caule e do consumo hídrico das plantas ao potencial osmótico da solução do solo, devido ao excesso de sais presentes, dificultando a absorção de água por parte da planta, fazendo com que ela precise de maior esforço energético para a absorção de água e de nutrientes, reduzindo-se, assim, o seu crescimento.

Os resultados da área foliar em função dos tratamentos salinos aplicados encontram-se na Figura 4A. A máxima produção foi obtida com a salinidade de $2,85 \mathrm{dS} \mathrm{m}^{-1}$, que corresponde a $21,4 \mathrm{~cm}^{2}$. A partir desse ponto verificase decréscimo de $24 \%$, quando se compara S1 com S5.
Oliveira et al. (2012) relatam que o maior valor de área foliar de rabanete irrigado com água salina foi obtido com aplicação do menor nível de salinidade $\left(2 \mathrm{dS} \mathrm{m}^{-}\right.$ ${ }^{1}$ ), obtendo-se 497,20 $\mathrm{cm}^{2}$, enquanto, no maior nível de salinidade $\left(10 \mathrm{dS} \mathrm{m}^{-1}\right)$, resultou no menor valor de área foliar, obtendo-se $220 \mathrm{~cm}^{2}$, correspondentes a uma redução de $55,75 \%$, reafirmando-se os dados obtidos neste estudo, mesmo com maiores concentrações de sais na água.

De acordo com Tester \& Davenport (2003), a salinidade reduz o potencial osmótico, refletindo na diminuição da absorção de água pelas plantas e comprometendo os processos fisiológicos; assim, as plantas podem apresentar modificações morfofisiológicas, a fim de aumentar sua tolerância à salinidade, com destaque para a redução da área foliar, em decorrência da diminuição do volume de células. Com redução da AF e aumento da concentração total de solutos na folha, ocorre ajustamento osmótico das células, garantindo às plantas a absorção de água.

De acordo com o modelo de regressão para comprimento de raiz (Figura 4B) o máximo valor, aos 27 dias após aplicação dos tratamentos salinos, foi atingido com 2,82 $\mathrm{dS} \mathrm{m}{ }^{-1}$, o que corresponde a 13,0 cm. Conforme Mohammad et al.(1998), o incremento da salinidade é acompanhado da redução do comprimento de raízes, confirmando-se com isso os resultados obtidos neste trabalho.

O modelo matemático que melhor se ajustou para a fitomassa seca da parte aérea, aos 27 dias após a aplicação dos tratamentos, foi o quadrático (Figura 5A) sendo obtido o máximo com $3,0 \mathrm{dS} \mathrm{m}^{-1}$ e a diferença de $20 \%$ entre o maior (S5) e o menor (S1) nível de salinidade. Chen \& Jiang (2010) afirmam que o efeito dos sais provoca redução da parte área de certas espécies em razão de não apresentarem um ajuste osmótico como mecanismo de adaptabilidade ao excesso de sais na solução do solo.

Para a variável fitomassa seca total (Figura 5B), aos 27 dias após aplicação dos tratamentos salinos, o máximo rendimento foi obtido com $3,5 \mathrm{dSm}^{-1}$ e corresponde a $0,25 \mathrm{~g}$.

Gondim et al. (2010), estudando a condutividade elétrica na produção e nutrição de alface em sistema de cultivo hidropônico NFT, também constataram que a fitomassa seca total apresentou resposta quadrática ao aumento da CE da solução, atingindo o máximo de 100,4 g com 2,68 mS $\mathrm{cm}^{-1}$. A partir dessa CE, houve uma redução de 7,1\% na MST com a CE de $4 \mathrm{mS} \mathrm{cm}^{-1}$.

Tabela 1: Análise química do solo utilizado no experimento

\begin{tabular}{|c|c|c|c|c|c|c|c|c|c|c|c|c|c|}
\hline pH & $\mathbf{P}$ & M.O & $\mathbf{K}$ & $\mathbf{C a}$ & Mg & Al & $\mathbf{H}+\mathbf{A l}$ & $\mathbf{T}$ & \multirow{2}{*}{$\frac{\mathrm{V}}{(\%)}$} & $\mathbf{F e}$ & $\mathrm{Cu}$ & $\mathbf{Z n}$ & \multirow[t]{2}{*}{ Mn } \\
\hline$\left(\mathrm{H}_{2} \mathrm{O}\right)$ & $\left(\mathrm{mg} \mathrm{dm}^{-3}\right)$ & $\left(\mathrm{g} \mathrm{dm}^{-3}\right)$ & \multicolumn{6}{|c|}{$\left(\mathrm{cmol}_{\mathrm{c}} \mathrm{dm}^{-3}\right)$} & & \multicolumn{3}{|c|}{$\left(\mathrm{mg} \mathrm{dm}^{-3}\right)$} & \\
\hline 5,7 & 13 & 15 & 0,2 & 1,4 & 1,4 & 0,2 & 4,0 & 7,0 & 42,9 & 44,5 & 0,86 & 2,4 & 32 \\
\hline
\end{tabular}

Rev. Ceres, Viçosa, v. 63, n.4, p. 509-516, jul/ago, 2016 
Houve efeito da salinidade $(\mathrm{p}<0,01)$ sobre FFPA, FFR, FFT, FSPA, FSR e FST. Houve efeito linear significativo ( $\mathrm{p}$ $<0,01$ ) sobre FFPA, FFR, FFT, FSPA, FSR e FST, em função da salinidade da água de irrigação, respectivamente. Resultados semelhantes foram observados por Silva et al. (2013), estudando as relações hídricas em cultivares de beterraba em diferentes níveis de salinidade do solo.
Hassanli et al. (2010), em estudos sobre a influência de métodos de irrigação e a qualidade da água na produção de beterraba açucareira, observaram efeito significativo da salinidade da água no crescimento. Atribui-se a redução dos valores ao potencial osmótico acrescido da solução do solo, em razão do excesso de sais presentes, dificultando a absorção de água por parte da planta, fazendo
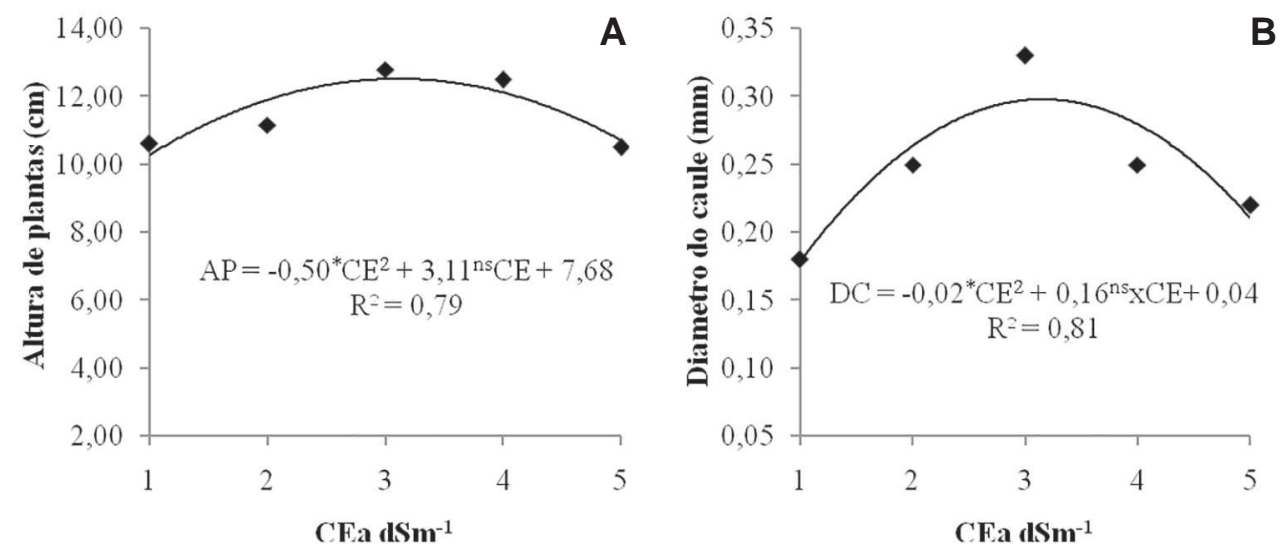

Figura 3: Altura de plantas (A) e Diâmetro do caule (B), aos 27 dias após aplicação dos tratamentos em função da salinidade da água de irrigação.
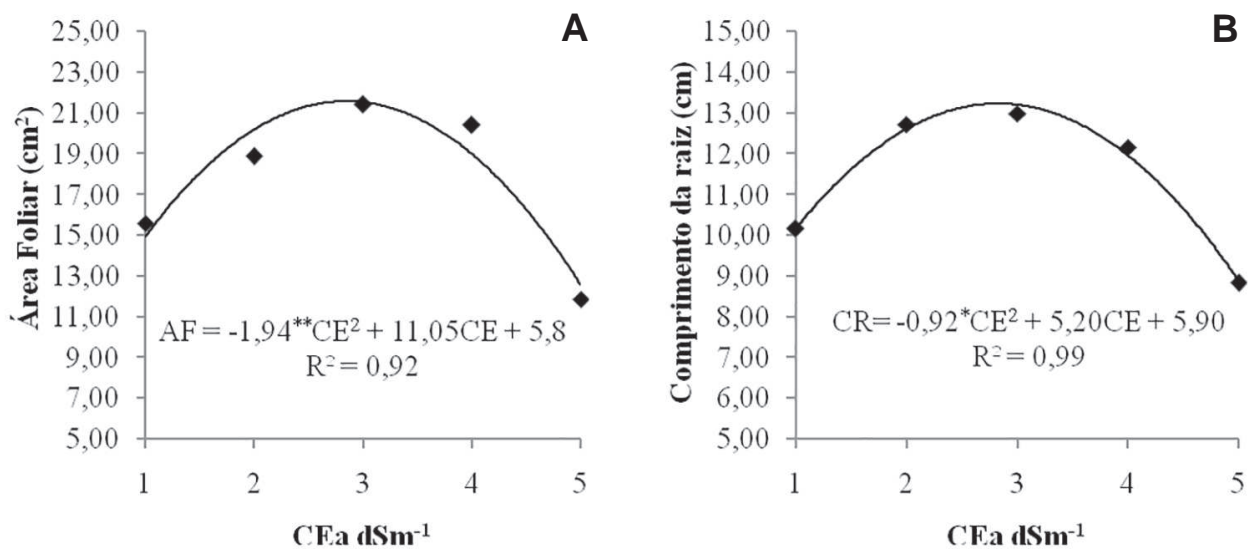

Figura 4: Área foliar (A) e Comprimento da raiz (B), aos 27 dias após aplicação dos tratamentos em função da salinidade da água de irrigação.
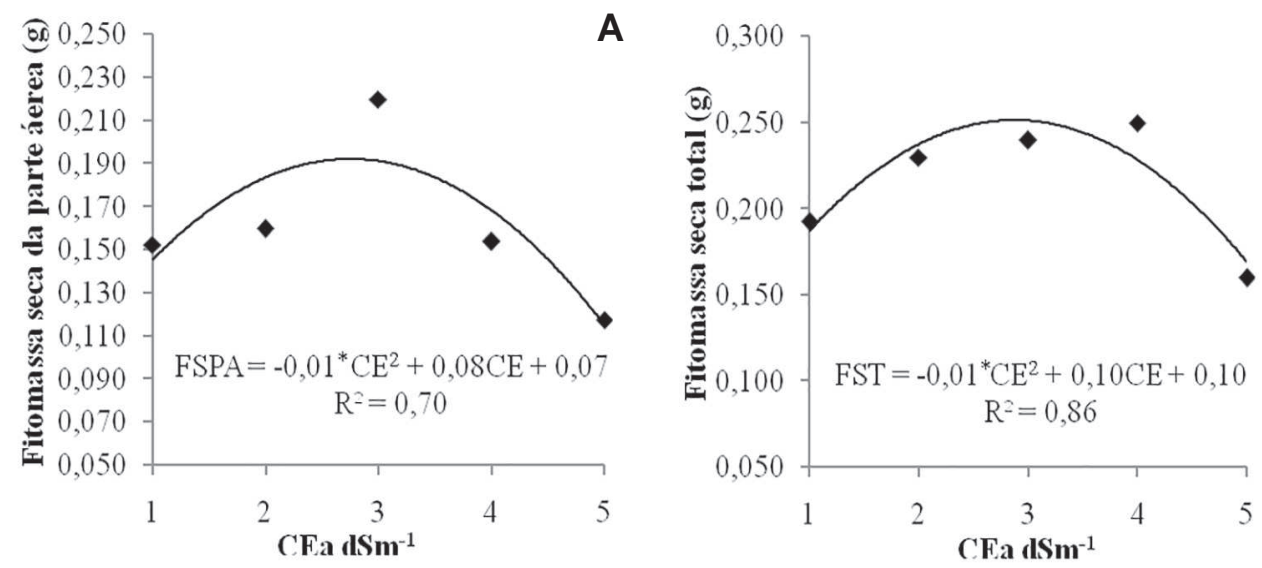

Figura 5: Fitomassa seca da parte aérea (A) e fitomassa seca total (B), aos 27 dias após aplicação dos tratamentos, em função da salinidade da água de irrigação. 
com que ela precise de maior esforço energético para a absorção de água e nutrientes, reduzindo-se, assim, seu crescimento (Silva, 2012).

Observa-se que, à medida que se aumentou a salinidade da água de irrigação, houve incremento da fitomassa fresca de parte aérea e de raiz aos 42 dias após aplicação dos tratamentos salinos (Figura 6A e B). Constata-se, ainda, que o maior rendimento para ambas as variáveis foi observado com $5 \mathrm{dSm}^{-1}$, correspondendo a 3,13 e $0,59 \mathrm{~g}$, respectivamente, o que, provavelmente pode ser justificado pela elevada precipitação durante o período experimental, acar- retando lixiviação dos sais presentes na zona radicular das plantas.

Esses resultados estão em desacordo com os encontrados em diversas pesquisas, como as de Putti et al. (2014); Paulus et al. (2010); Silva et al. (2013); Silva et al. (2014) e Silva et al. (2014), estudando o efeito dos sais nas diversas culturas. Segundo Greenway \& Munns (1980), o cultivo, com $200 \mathrm{mM}$ de $\mathrm{NaCl}$, por um dado período de tempo, poderá acarretar a morte de espécies sensíveis, como o feijão, provocar reduções de até $60 \%$ na biomassa de es-

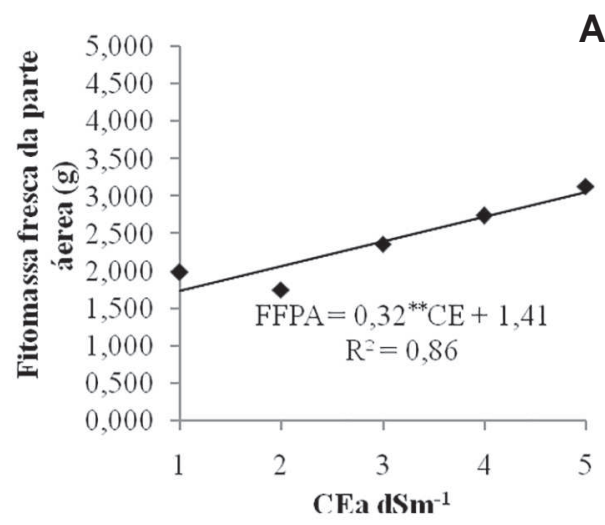

A

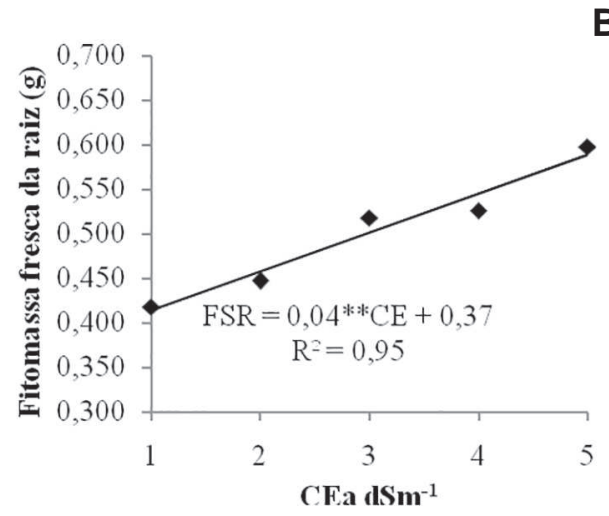

Figura 6: Fitomassa fresca da parte aérea (A) e fitomassa fresca da raiz (B), aos 42 dias após aplicação dos tratamentos, em função da salinidade da água de irrigação.
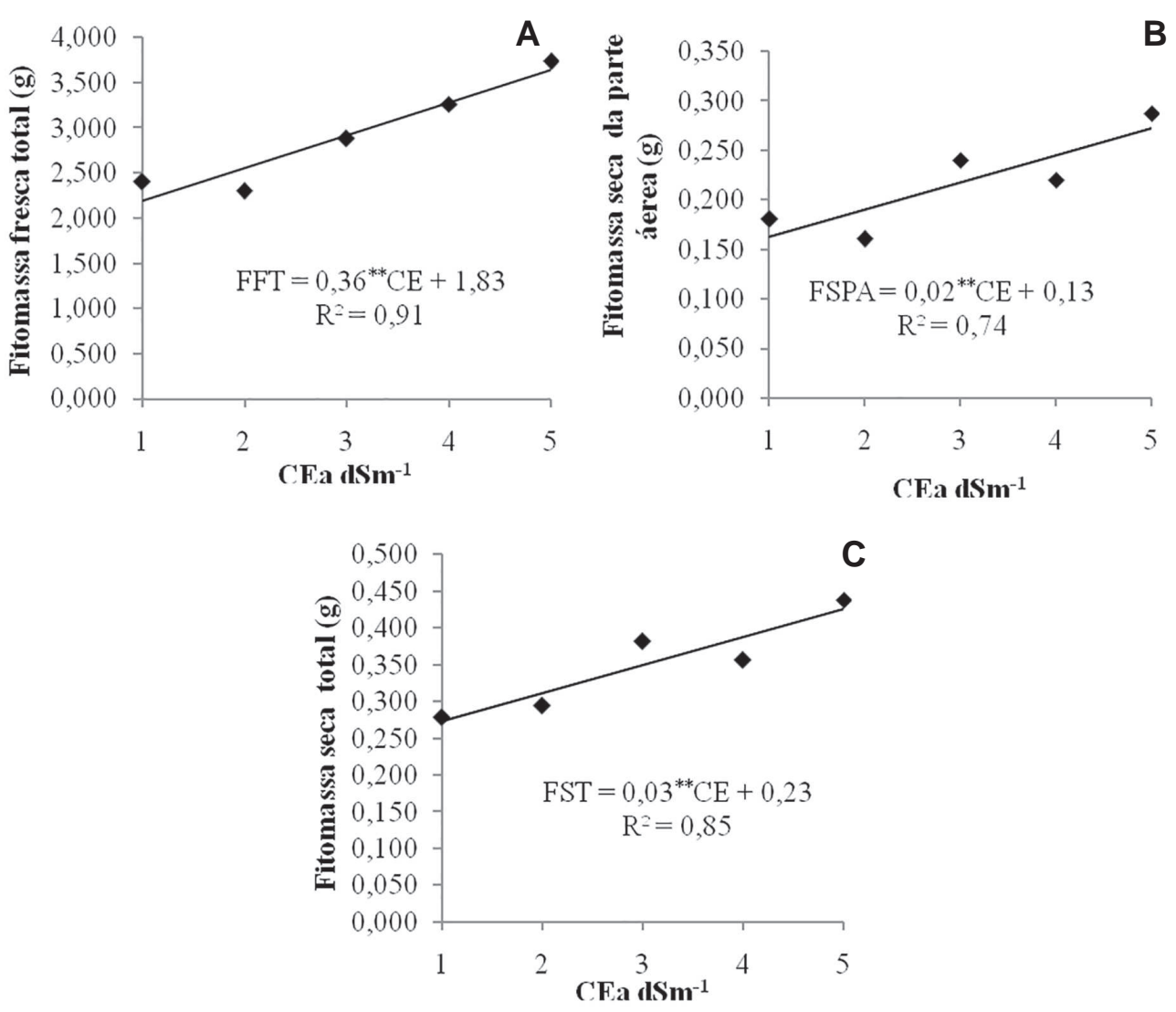

Figura 7: Fitomassa fresca total (A), fitomassa fresca da parte aérea (B) e fitomassa seca total (C), aos 42 dias após aplicação dos tratamentos, em função da salinidade da água de irrigação. 
pécies como o algodão, ou reduzir em $20 \%$ o peso da matéria seca da beterraba.

De acordo com os estudos de regressão, o modelo matemático que melhor se ajustou aos dados de fitomassas fresca total, seca da parte aérea e seca total foi o linear, aos 42 dias após aplicação dos tratamentos salinos (Figuras 7A, B e C).

Verificou-se que, à medida que aumenta a salinidade da água de irrigação, houve acréscimo das fitomassas das plantas de beterraba, sendo o maior valor observado com a salinidade de $5 \mathrm{dS} \mathrm{m}^{-1}$, correspondendo a 3,73;0,28 e $0,48 \mathrm{~g}$, respectivamente, para as fitomassas fresca total, seca da parte aérea e seca total. No entanto, esse aumento da massa pode estar relacionado com o fato de as folhas nos níveis mais altos apresentarem-se mais grossas e menos flexíveis, o que pode estar associado ao fato de a cultura da beterraba ser considerada tolerante aos efeitos dos sais, sendo que, para uma salinidade de 4,7 $\mathrm{dSm}^{-1}$, não há redução do rendimento da cultura. Assim, como os tratamentos estudados estão dentro da salinidade tolerada pela cultura, não se verificaram perdas e rendimento (Ayers \& Westcott, 2001). No entanto, deve-se atentar para as chuvas ocorridas no período, que podem ter lixiviado os sais do solo, comprometendo o resultado da pesquisa.

No entanto, vale ressaltar, a tolerância depende da habilidade da planta em controlar o transporte de sais em cinco pontos específicos: - seletividade no processo de absorção pelas células das raízes; - carregamento do xilema preferencialmente com $\mathrm{K}^{+}$, mais do que com $\mathrm{Na}^{+}$; - remoção do sal do xilema na parte superior das raízes, caule, pecíolo ou bainhas foliares; - retranslocação de $\mathrm{Na}^{+} \mathrm{e} \mathrm{Cl}$ no floema, garantindo a ausência de translocação para tecidos da parte aérea em processo de crescimento, e excreção de sais por glândulas ou pelos vesiculares (Munns et al, 2002).

\section{CONCLUSÕES}

Os valores máximos na beterraba, aos 27 dias após aplicação dos tratamentos salinos, foi obtido com uma salinidade de 3,0 dS m${ }^{-1}$, para as variáveis altura de planta, diâmetro do caule, comprimento da raiz, fitomassa seca da parte aérea e fitomassa seca total.

Aos 42 dias após aplicação dos tratamentos salinos, as variáveis fitomassa fresca da parte aérea, fitomassa fresca da raiz, fitomassa fresca total, fitomassa seca da parte aérea e fitomassa seca total aumentaram com o aumento da salinidade da água.

As chuvas podem ter influenciado o resultado obtido na avaliação realizada aos 42 dias após aplicação dos tratamentos salinos.

\section{REFERÊNCIAS}

Aquino LA de, Puiatti M, Pereira PRG, Pereira FHF, Ladeira IR \& Castro MRS (2006) Produtividade, qualidade e estado nutricional da beterraba de mesa em função de doses de nitrogênio. Horticultura Brasileira, 24:199-203.

Ayers RS \& Westcot DW (1991) Qualidade de água na agricultura. Campina Grande, UFPB. 218p. (Estudos FAO. Irrigação e Drenagem, 29).

Chen H \& Jiang J (2010) Osmotic adjustment and plant adaptation to environmental changes related to drought and salinity. Environmental Reviews, 18:309-319.

Ferreira DF (2008) Sisvar: um programa para análises e ensino de estatística. Revista Symposium, 6:36-41.

Ferreira PA, Moura RF de, Santos DB dos, Fontes PCR \& Melo RF de (2006) Efeitos da lixiviação e salinidade da água sobre um solo salinizado cultivado com beterraba. Revista Brasileira de Engenharia Agrícola e Ambiental, 10:570-578.

Filgueira FAR (2008) Novo manual de olericultura: Agrotecnologia moderna na produção e comercialização de hortaliças. $3^{\text {a }}$ ed. Viçosa, UFV. 421 p.

Gondim ARO, Flores MEP, Martinez HEP, Fontes PCR \& Pereira PRG (2010) Condutividade elétrica na produção e nutrição de alface em sistema de cultivo hidropônico nft. Bioscience Journal, 26:894-904.

Greenway H \& Muuns R (1980) Mechanisms of salt tolerance in nonhalophytes. Annual Review of plant physiology. $31^{\mathrm{a}} \mathrm{ed}$. Nedlans, Web of Science. 41p.

Hassanli AM, Ahmadirad S \& Beecham S (2010) Evaluation of the influence of irrigation methods and water quality on sugar beet yield and water use efficiency. Agricultural Water Management, 97:357-362.

Katerji N, Hoom JW, Hamdy A, Mastrorilli M \& Karzel EM (1997) Osmotic adjustment of sugar beets in response to soil salinity and its influence on stomatal conductance, growth and yield. Agricultural Water Management, 34:57-69.

Munns R, Husain S, Rivelli AR, Richard AJ, Condon AG, Megan P, Evans S, Schachtman DP \& Hare RA (2002) Avenues for increasing salt tolerance of crops, and the role of physiologically based selection traits. Plant and Soil, 247:93-105.

Mohammad M, Shibli R \& Ajouni M (1998) Tomato root and shoot responses to salt stress under different levels of phosphorus nutrition. Journal of Plant Nutrition, 21:16671680 .

Oliveira AMP, Oliveira AM, Dias NS, Freitas M \& Silva KB (2012) Cultivo de rabanete irrigado com água salina. Revista Verde de Agroecologia e Desenvolvimento Sustentável, 7:01-05.

Paulus D, Dourado Neto D, Frizzone JA \& Soares TM (2010) Produção e indicadores fisiológicos de alface sob hidroponia com água salina. Horticultura Brasileira, 28:29-35.

Putti FF, Silva Junior JF, Ludwig R, Gabriel Filho RA, Cremasco CP \& Klar AE (2014) Avaliação da cultura do rabanete ao longo do ciclo submetido em diferentes níveis de salinidade. Journal of Agronomic Sciences, 3:80-90.

Rhoades JD (1974) Drainage for salinity control. In: Shilfgaarde J van (Ed.) Drainage for Agriculture. Salt Lake City, American Society of Agronomy. p.433-462.

Richards LA (1954) Diagnosis and improvement of saline and alkali soils: united statessalinity laboratory. $60^{\mathrm{a}}$ ed. Washington, Agriculture Handbook. 160p. 
Santos AN, Soares TM, Silva EFF, Silva DJR \& Montenegro AAA (2010) Cultivo hidropônico de alface com água salobra subterrânea e rejeito da dessalinização em Ibimirim, PE. Revista Brasileira de Engenharia Agrícola e Ambiental, 14:961-969.

Silva AO (2012) Fertirrigação e controle da salinidade em cultivo de beterraba em ambiente protegido. Dissertação de Mestrado. Universidade Estadual Paulista, Botucatu. 137p.

Silva AO, Klar AE, Silva EFF \& Cunha AR (2014) Evapotranspiração e coeficiente de cultivo para a beterraba sob estresse salino em ambiente protegido. Irriga, 19:375-389.

Silva AO, Klar AE, Silva EFF, Tanaka AA \& Silva Junior JF (2013) Relações hídricas em cultivares de beterraba em diferentes níveis de salinidade do solo. Revista Brasileira de Engenharia Agrícola e Ambiental, 17:1143-1151.
Silva AO, Soares TM, Silva EFF, Santos AN \& Klar AE (2012) Consumo hídrico da rúcula em cultivo hidropônico nft utilizando rejeitos de dessalinizador em Ibimirim-pe. Irriga, 17:114125

Silva PF, Cavalcante VS, Santos JCC, Costa ES \& Barbosa JTV (2014) Análise quantitativa da cebolinha irrigada com água salina. Comunicata Scientiae, 5:241-251.

Tester M \& Davenport R (2003) $\mathrm{Na}^{+}$tolerance and $\mathrm{Na}^{+}$transport in higher plants. Annals of Botany, 91:503-527. 